\title{
Rupture of undiagnosed embryonal rhabdomyosarcoma after shock wave lithotripsy in an 11-year-old girl
}

\author{
Yu Seob Shin, MD; ${ }^{*}$ Young Gon Kim, MD; ${ }^{*}$ Kyu Yun Jang, MD; Hwang Choi, MD; ${ }_{;}^{+}$Hyung Jin Kim, MD*
}

*Department of Urology, Chonbuk National University Medical School, Jeonju, South Korea; 'Department of Pathology, Chonbuk National University Medical School, Jeonju, South Korea; ${ }^{\S}$ Armed Forces Capital Hospital, Seongnam, South Korea

Cite as: Can Urol Assoc J 2014;8(11-12):e878-80. http://dx.doi.org/10.5489/cuaj.1846 Published online November 24, 2014.

\section{Abstract}

We present a case of a rupture of an undiagnosed embryonal rhabdomyosarcoma after shock wave lithotripsy (SWL) in an 11-year-old girl. Although SWL is generally regarded as safe, careful imaging before SWL is important to prevent life-threatening complications in children.

\section{Introduction}

The treatment of urolithiasis in children has gained more attention from pediatric urologists, possibly due to the increasing incidence of kidney and ureteral stones. ${ }^{1}$ The efficacy of shock wave lithotripsy (SWL) to treat urinary stones in children is higher than in adults. The pediatric ureter is shorter and more elastic, which makes stone passage easier and less fragmented. ${ }^{2}$ SWL, however, is not without its minor and major complications. SWL acts on stones via cavitation, shear and spelling, resulting in stone fragmentation; these forces may injure vessels in the kidney or adjacent tissues, and hemorrhagic complications can ensue. ${ }^{3}$ We present a case of rupture of undiagnosed embryonal rhabdomyosarcoma after SWL in an 11-year-old girl.

\section{Case report}

An 11-year-old girl presented to the emergency department with left-sided abdominal pain. Two days before, she underwent SWL at a local clinic for left upper ureteral stone, initially diagnosed by intravenous pyelography (IVP) (Fig. 1). She underwent SWL using 40 shock waves per minute with electrohydraulic shock wave lithotripter. Total shock was 1200 times during 30 minutes of SWL. After treatment, abdominal pain gradually developed, which was aggravated by changes in position. Gross hematuria was not observed. At presentation, her blood pressure was 80/40 $\mathrm{mmHg}$ and pulse rate was 85 . On physical examination, her abdomen was distended and rebound tenderness was detected in the left lower abdomen. Hemoglobin level was $9.3 \mathrm{~g} / \mathrm{dL}$. Magnetic resonance imaging of the abdomen revealed a huge retroperitoneal mass rupture with hemoperitoneum (Fig. 2). Exploration revealed a tumour apparently originating in the retroperitoneal space anterior to the psoas muscle. The tumour was adherent to surrounding tissues and encircled the left upper ureter at the 5th lumbar vertebra level. A large amount of retroperitoneal hemorrhage was observed. Complete tumorectomy and clot evacuation were performed. Pathologic evaluation revealed a rupture of embryonal rhabdomyosarcoma (Fig. 3). She was discharged on postoperative day 4 without complications and is receiving adjuvant chemotherapy for embryonal rhabdomyosarcoma elsewhere.

\section{Discussion}

The incidence and characteristics of urolithiasis in children reflect a wide geographic variation, but stones occur in children of all ages without clear gender predominance. ${ }^{4}$ Urological management of urolithiasis in children has evolved dramatically over the past 3 decades from open surgical to percutaneous, endoscopic and extracorporeal options. A large series of SWL in children demonstrated complications, safety and stone-free rates similar to those in adults. ${ }^{5}$

Although SWL has generally been accepted as a safe procedure, major complications have been reported after SWL. 3,6 These complications include transient gross hematuria, flank pain, urinary tract infection, and hematoma, which usually can be managed conservatively. However, an 


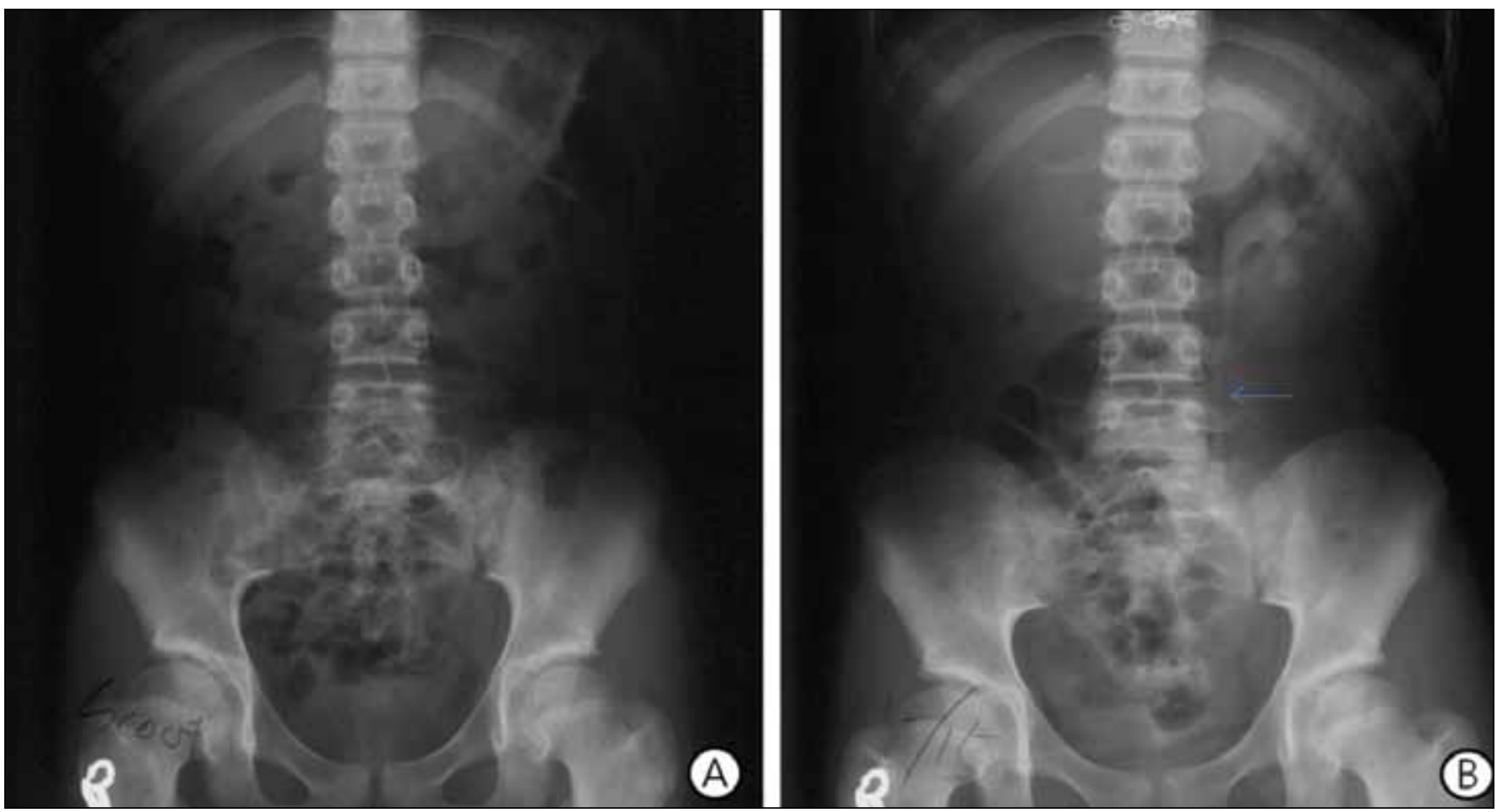

Fig. 1. Image of intravenous pyelography before shock wave lithotripsy. A: Scout image showing radiolucent urinary stone. B: Image 3 hours after injection of intravenous contrast media showing left upper ureteral stone (arrow) with hydronephrosis.

extremely small number of cases require transfusion or surgical treatment due to the development of clinically significant hemorrhage. ${ }^{7}$ In cases where signs of hypovolemic shock and hemmorhage are suspected, appropriate resuscitation and timely imaging are indicated. In patients who do not respond to transfusion and supportive care, embolization or surgical treatment might be considered. ${ }^{8}$

Rhabdomyosarcoma is a malignant neoplasm arising from skeletal muscle progenitors. In children, rhabdomyosarcoma it is the most common soft tissue tumour, responsible for
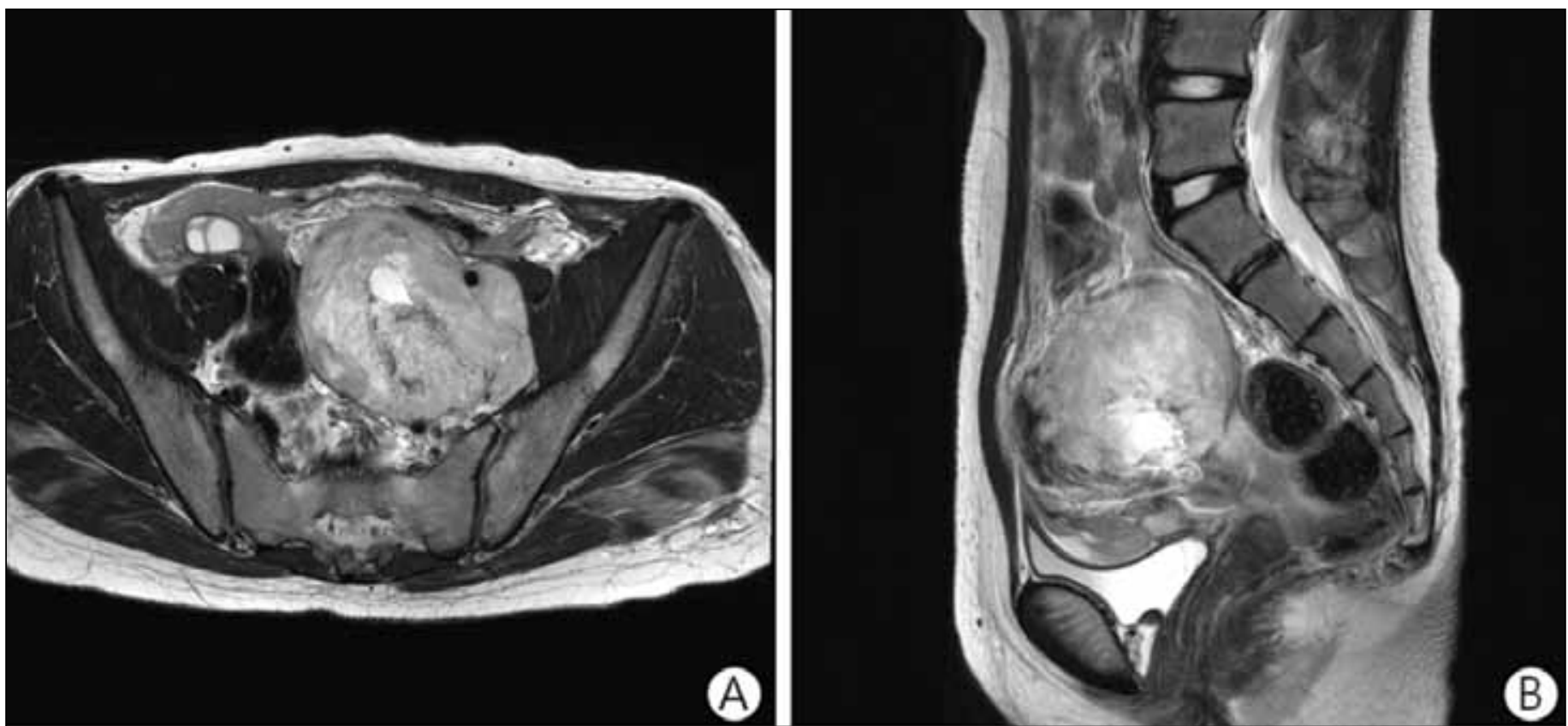

Fig. 2. A: Axial view and B: coronal view of magnetic resonance image showing rupture of huge retroperitoneal mass. 


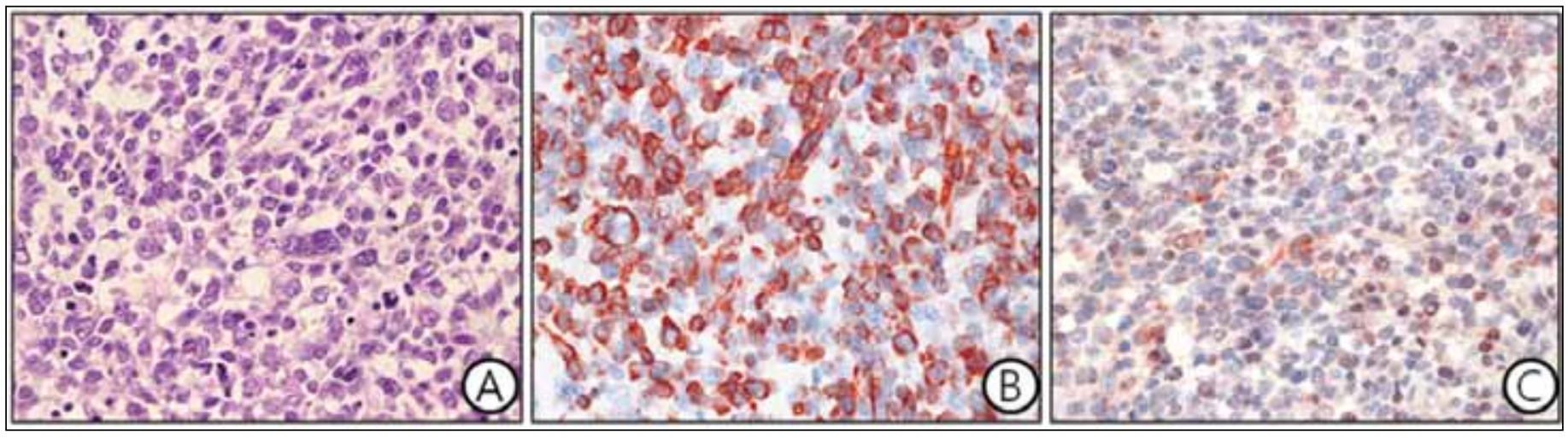

Fig. 3. A: Histologically, rhabdomyosarcoma composed of pleomorphic round to oval tumour cells. B: Consistent with the diagnosis of rhabdomyosarcoma, the tumour cells were strongly positive for desmin. C: Weakly positive for MyoD1 (original magnification $\times 400$ ).

about $50 \%$ of all soft tissue sarcomas and $3 \%$ to $4 \%$ of all cancers in children. ${ }^{9}$ The genitourinary tract is the second most common primary tumour location and about $20 \%$ of rhabdomyosarcomas in children arise in the genitourinary tract. $^{9}$

In our young patient, IVP was only imaging study and hence the rhabdomyosarcoma was missed before performing SWL. A combination of ultrasound and plain film is a safe and effective imaging study for children suspected ureteral stone..$^{10}$ This tactic avoids radiation and contrast reaction in children suspected as having urolithiasis. In the West, this combination has replaced the IVP and even computed tomography scans.

\section{Conclusion}

In our case, ultrasound may also have alerted us to the tumour. Whether the SWL caused the tumour to rupture is uncertain. Notwithstanding the chronology, symptom escalation and the signs of hypovolemia and anemia, including tumour location, we suspected an association with SWL.

Competing interests: Dr. Shin, Dr. YG Kim, Dr. Jang, Dr. Choi and Dr. HJ Kim all declare no competing financial or personal interests.

\section{References}

1. VanDervoort K, Wiesen J, Frank R, et al. Urolithiasis in pediatric patients: A single center study of incidence, clinical presentation and outcome. J Urol 2007;177:2300-5. http://dx.doi.org/10.1016/i. juro.2007.02.002

2. Reusz GS, Dobos M, Byrd D, et al. Urinary calcium and oxalat excretion in children. Pediatric Nephrol 1995;9:39-44. http://dx.doi.org/10.1007/BF00858966

3. Skolarikos $A$, Alivizatos $G$, de la Rosette J. Extracorporeal shock wave lithotripsy 25 years later: Complications and their prevention. Eur Urol 2006;50:981-90. http://dx.doi.org/10.1016/..eururo.2006.01.045

4. Sternberg K, Greenfield SP, Williot $P$, et al. Pediatric stone disease: An evolving experience. J Urol 2005;174:1711-4. http://dx.doi.org/10.1097/01.ju.0000179537.36472.59

5. Newman DM, Coury T, Lingeman JE, et al. Extracorporeal shock wave lithotripsy experience in children. J Urol 1986;136:238-40.

6. Doran 0 , Foley B. Acute complications following extracorporeal shock-wave lithotripsy for renal and ureteric calculi. Emerg Med Australas 2008;20:105-11. http://dx.doi.org/10.1111/j.1742$6723.2008 .01065 x$

7. Fukumori T, Yamamoto A, Ashida $S$, et al. Extracorporeal shock wave lithotripsy-induced renal laceration. Int J Urol 1997;4:419-21. http://dx.doi.org/10.1111/i.1442-2042.1997.tb00219.x

8. Collado Serra A, Huguet Pérez J, Monreal García de Vicu-a F, et al. Renal hematoma as a complication of extracorporeal shock wave lithotripsy. Scand J Urol Nephrol 1999;33:171-5. http://dx.doi. org/10.1080/003655999750015943

9. Ferguson SE, Gerald W, Barakat RR, et al. Clinicopathologic features of rhabdomyosarcoma of gynecologic origin in adults. Am J Surg Pathol 2007;31:382-9. http://dx.doi.org/10.1097/01. pas. 0000213352.87885 .75

Correspondence: Dr. Hyung Jin Kim, Department of Urology, Chonbuk National University Medical School, Jeoniu, South Korea; hikim@jbnu.ac.kr

This paper has been peer-reviewed. 